\title{
PERFORMANCE ANALYSIS OF VLJ AIRCRAFTS
}

\author{
Lucio Garcia Veraldo Junior* \\ Sao Paulo State University \\ Guaratingueta, SP, Brazil \\ E-mail: lucioveraldo@uol.com.br \\ Mauricio Cesar Delamaro \\ Sao Paulo State University \\ Guaratingueta, SP, Brazil \\ E-mail: delamaro@,feg.unesp.br \\ Paulo Cesar De Carli \\ Sao Paulo State University \\ Guaratingueta, SP, Brazil \\ E-mail: decarli.gta@uol.com.br \\ Valerio A. P. Salomon \\ Sao Paulo State University \\ Guaratingueta, SP, Brazil \\ E-mail: salomon@feg.unesp.br
}

\begin{abstract}
A new option of air transport has appeared for the strictest customers, who have no time to lose with going to airports, waiting in line, or for those who enjoy travelling or even flying their own airplanes. That is the new VLJ airplanes, which provide private flights at costs not yet offered by any companies. Aircraft manufacturers are developing these airplanes, searching to fulfill this new market opportunity. This paper aims to present an overall performance analysis of five of these airplanes. The features used by a public tool in the www were considered as the decision criteria. At first, the AHP was applied in order to obtain the criteria weights. Then, using the known performance values for the airplanes, the one with the best overall performance was identified. A second analysis, also using AHP method was carried out, this time replacing performance values by judgments from an aviation market expert.
\end{abstract}

Keywords: AHP; Airplanes; Performance Analysis; VLJ.

\section{Introduction}

In Brazil we have three major airlines companies offering services. The Brazilian Civil Aviation Agency says these companies offer only 44 destinations, in a country with 5,500 cities and towns (Silva, 2008). If services offered by minor companies are also considered, the total number of Brazilian cities and towns that can be reached comes up to about 130. Whatever the explanation might be, economic viability, financial power of the population, high air-ticket costs etc., this service is below what most people could afford.

On the other hand, major airports are quickly getting crowded due to demand increases for airplane trips. At busy airports, the problems of dealing with increasing passenger numbers bring about baggage loss complaints, lines, increasing security measures, delays in departures or arrivals, cancellations, waits, doubts on boarding ramps, and so on.

* Corresponding author 
Aircraft manufacturers, aware of the opportunities offered by this scenario, and taking advantage of the development of engine and equipment technology, have invested on developing jet airplanes for corporative use as well as for other uses, which, by convention, are being called VLJ (Very Light Jets). According to the National Business Aviation Association (2009), the expression VLJ is used to identify very light airplanes equipped with jet turbines and with a maximum take-off weight of under 10,000 pounds (about $4,543 \mathrm{~kg}$ ), with certification to be operated by a single pilot. For means of comparison, great airplanes weigh over 12,500 pounds, whilst light ones have a lower weight.

VLJ can transport four to five passengers up to a $930 \mathrm{~km}$ distance. They are airplanes which have operational low costs as well as acquisition price similar to that of a turbo-prop aircraft, characteristics that promise to turn this new category into a success in sales.

The aim of this paper is to present results from a performance analysis of five VLJ airplanes, having as criteria the major features of this kind of airplane. The AHP (Analytic Hierarchy Process) method was applied in this analysis. In addition, via an expert on the area of business aviation and small airplanes, judgments were elaborated by considering the collected criteria as well as through the analysis from the AHP method.

\section{Buyer's Market}

There are several kinds VLJ aircraft buyers (Strait, 2007).

\subsection{Private Owners}

Airplanes are purchased for owners' personal use. These owners search for pleasure in the speed and safety of their trips, at costs lower than those known up to some years ago.

\subsection{Pilot Owners}

Pilots are also buying their own VLJ airplanes. Or, at least, they are planning to buy, so they can finally afford flying their own jets.

\subsection{Air Taxi Operators}

These operators are optimistic towards the new concept of VLJ airplanes. After all, these airplanes are smaller, and more comfortable, and they may increase flexibility in many ways and frontiers, enabling a better service to meet customers' needs.

\subsection{Freight Operators}

These operators search around the world for the best and most economic VLJ airplanes.

\subsection{Private Companies}

Even the smallest corporations can finally observe the benefits brought by trips on private jets, because of the reduced costs offered by VLJ airplanes. As they make it possible to avoid big airports, making use of smaller ones, business trips can be made on the same day. Many companies are purchasing these airplanes individually or as fleets.

\section{Choosing AHP}

When problems require the use of a method that helps decision making by using multiple criteria, its application must be analyzed, mainly with regard to the inconsistency of its criteria evaluation, so as to provide consistent results (Veraldo Junior, 2008). The AHP method has as an advantage to force the decision maker to think about the decision in a rational and hierarchical way (Ghotb and Warren, 1995). As a disadvantage, it presents the limit of a maximum of nine elements simultaneously compared. 
The dynamics of the decision making process, when based on the AHP method, leads to a wider discussion of the decision process. Thus, it equalizes the criteria and sub-criteria involved in the decision, minimizing natural distortions, subjective aspects, and the traps which are usually present in a decision making processes (Murakami, 2003).

These aspects make possible to assert the decision quality, one of the intrinsic characteristics of the AHP method. Thus, pointing out that danger lies not on a wrong definition, but on a plausible, though incomplete definition (Drucker, 1967).

\subsection{AHP Method}

The AHP method has as its basis the representation of a complex problem through its hierarchical organization, aiming at prioritizing factors in the various alternative analyses. This process involves four basic steps: hierarchy structure, pairwise comparisons at each system level, and principles of prioritizing and synthesizing priorities.

The hierarchy structure step consists of the definition of a global objective, and the decomposition of the system into hierarchy levels. This organization enables the visualization of the system as a whole and its components, as well as these components and the impact they have on the system itself. The hierarchy is formed by the events and their respective relationships, and it can be simple or compound (Lucena, 1999).

Simple hierarchy is formed by three levels. The first level is composed of one single element, the general aim or objective. The second level represents the criteria, and the third one represents the alternatives. The two latter levels can have various elements.

Complex hierarchy includes: general objective; environmental factors of physical, biological, chemical and other orders; general criterion including economic, social, political, technological, and ideological factors; sub-criteria regarding each criterion; groups which control criteria and subcriteria; involved groups' objectives; policies or factors which influence decision making and alternative plans.

Pairwise comparisons must be performed by an individual or a group who have experience on the problem being dealt with, and they can represent interest groups. This consists of a comparative judgment by attributing weights, in which one tries to determine the relative importance of each element of a certain hierarchy level with respect to each criterion on the higher level lying just above it. These weights are determined by a scale of judgments suggested by Saaty (1990), ranging from 1, when criteria are of equal importance, to 9 , for absolute importance from one criterion to another. The same represent dominion intensity of a given element upon another. From these, a pairwise comparison matrix is then constructed.

Pairwise comparisons are represented inside a square matrix whose elements are the weights attributed to the comparison between two elements $i$ and $j$. It is pointed out that this is a reciprocal matrix in which every element $a_{i j}$ corresponds to $a_{j i}=1 / a_{i j}$ and every $a_{i i}=1$.

The matrix could present inconsistency among the judgments. This inconsistency is tolerable up to a certain limit. Via the comparison matrix, the relative priority vector is obtained through an eigenvector which makes it possible to determine the degree of element importance in each hierarchy level, being this the stage for prioritization of system elements.

Next and last step is the priority-synthesizing, aiming at defining the global priority of alternative plans, by means of multiplying the matrix elements of related priorities of these plans, by the relative priorities of criteria. 


\subsection{Hierarchy Structure}

Evaluation criteria to determine the best business jet under VLJ category, to start with, must have the construction of a structure identifying the goal, the criteria and the alternatives, respectively, through hierarchy levels, as shown in Figure 1.

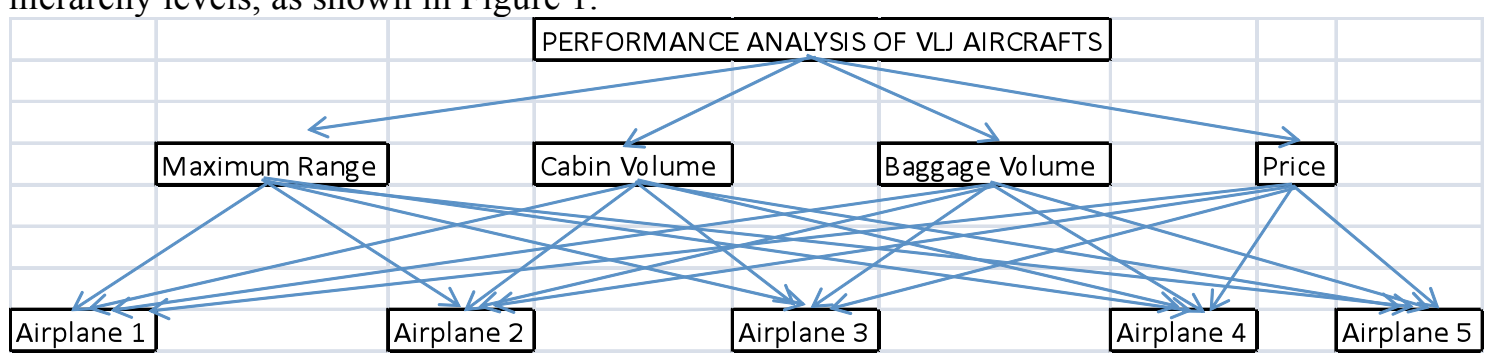

Figure 1. Hierarchy structure for determining the best VLJ airplane.

Selected criteria refer to aircraft performance indicators, and the alternatives refer to the aircraft themselves.

\subsection{Building Pair wise Comparison}

The matrix objective is to make comparison of the criteria defined for the problem. Numerical values from 1 to 9 will be used in order to judge each criterion with regard to another in a consistent way.

An expert on product strategy and business jet market intelligence, which had an eight-year experience in a big company, was requested to perform the judgment of the criteria. With these data, the matrix was elaborated by analyst, according to Figure 2.

Table 1. Pairwise comparison of VLJ performance criteria.

\begin{tabular}{|l|c|c|c|c|c|}
\cline { 2 - 6 } \multicolumn{1}{c|}{} & MR & CV & BV & P & Priority \\
\hline MR (Maximum Range) & 1 & $1 / 7$ & $1 / 3$ & $1 / 5$ & 0.056 \\
\hline CV (Cabin Volume) & & 1 & 3 & 5 & 0.573 \\
\hline BV (Baggage Volume) & & & 1 & 3 & 0.235 \\
\hline P (Price) & & & & 1 & 0.136 \\
\hline
\end{tabular}

In order to validate the matrix above, that is, to analyze whether the judgments made by the expert are consistent, the consistency indicator regarding the pairwise comparisons performed has to be calculated. This indicator has to be compared with a random index, computedby the National Laboratory of Oak Ridge, USA (Machado et al., 2003).

The consistency indicator was calculated and the judgments in Table 1 were consistent. The priority vector could then be used as weights for the criteria.

\section{Using available data}

This section presents an analysis using the designed data for the selected criteria of real aircrafts, as a way of verifying whether the performance of each aircraft meets the needs of major VLJ buyers.

Among the various characteristics of such airplane, the most important were selected, according to experts on small business jet aviation. These criteria are shown on Table 2.

Table 2. Evaluation criteria of VLJ aircrafts performance (Source: Kewljets, 2008). 


\begin{tabular}{|c|c|c|c|c|}
\hline \multirow{2}{*}{ Aircraft } & \multicolumn{4}{|c|}{ Performance Criteria } \\
\cline { 2 - 5 } & $\begin{array}{c}\text { Max Range } \\
\text { (nautical miles) }\end{array}$ & $\begin{array}{c}\text { Cabin Volume } \\
\text { (cubic feet) }\end{array}$ & $\begin{array}{c}\text { Baggage Volume } \\
\text { (cubic feet) }\end{array}$ & $\begin{array}{c}\text { Price } \\
\text { (US\$) }\end{array}$ \\
\hline Airplane 1 & 1,160 & 305 & 55 & $2,850,000$ \\
\hline Airplane 2 & 1,150 & 230 & 57 & $2,620,000$ \\
\hline Airplane 3 & 1,215 & 160 & 26 & $1,520,000$ \\
\hline Airplane 4 & 1,100 & 245 & 25 & $2,250,000$ \\
\hline Airplane 5 & 1,300 & 272 & 45 & $4,180,000$ \\
\hline
\end{tabular}

In order to equalize the criteria mentioned above, the values need to be normalized, aiming at comparing them under the same numerical basis, that is, the sum of the values for the five aircrafts, for each characteristic, equals 1 . This normalization is shown on Figure 2.

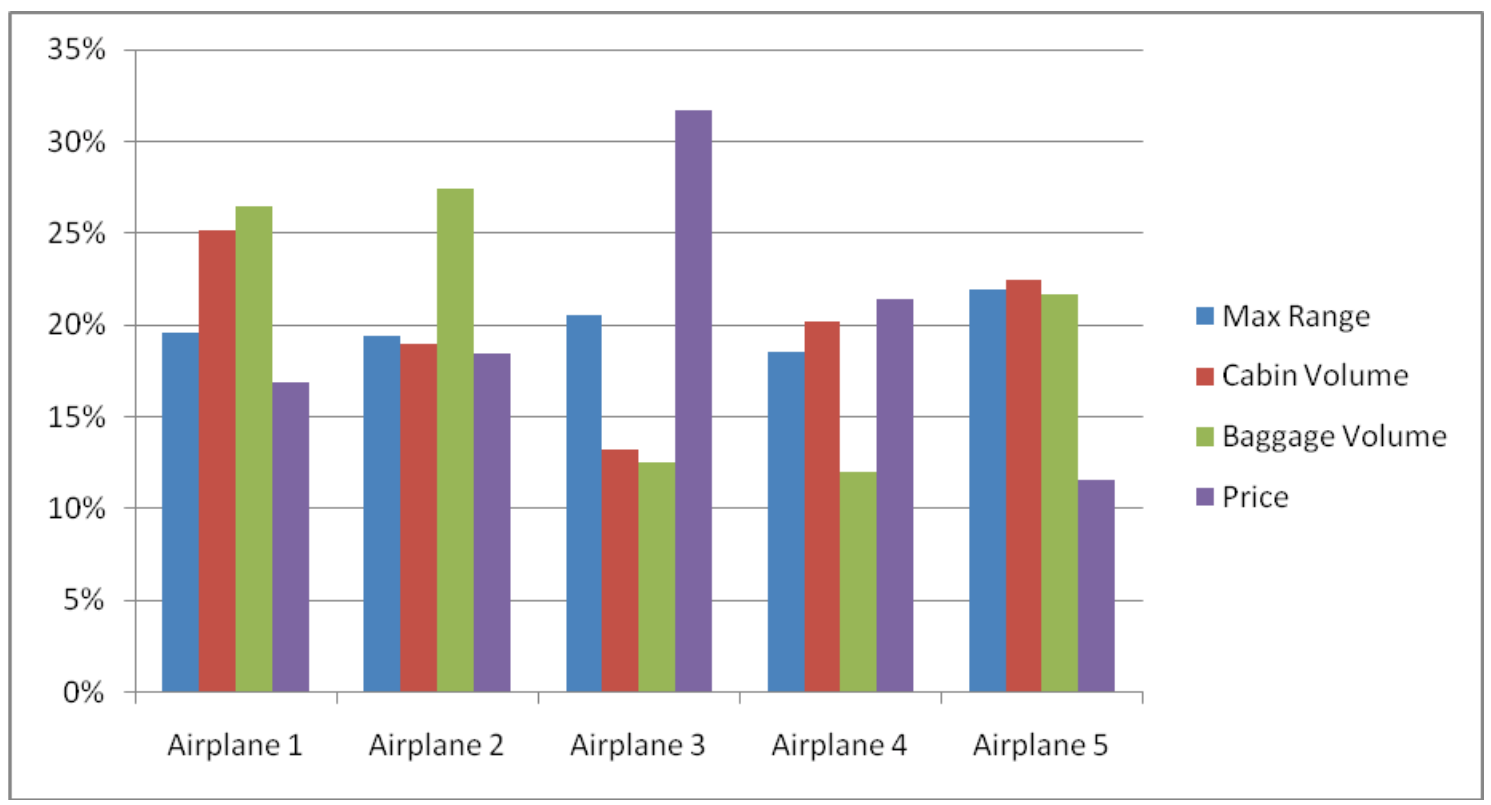

Figure 2. Performance values of VJL aircrafts.

The Overall Performance Vector can be obtained multiplying a matrix with the performance values of each plane, according to each criterion, by the criteria priorities (Table 1). Table 3 presents this matrix and the decision vectors. 
Table 3.Overall performance from data.

\begin{tabular}{|c|c|c|c|c|c|}
\cline { 2 - 5 } \multicolumn{1}{c|}{} & $\begin{array}{c}\text { Maximum } \\
\text { Range }\end{array}$ & Cabin Volume & $\begin{array}{c}\text { Baggage } \\
\text { Volume }\end{array}$ & Price & $\begin{array}{c}\text { Overall } \\
\text { Performance }\end{array}$ \\
\cline { 2 - 5 } & 0.056 & 0.573 & 0.235 & 0.136 & \\
\hline Airplane 1 & 0.196 & 0.252 & 0.264 & 0.169 & 0.240 \\
\hline Airplane 2 & 0.194 & 0.190 & 0.274 & 0.184 & 0.209 \\
\hline Airplane 3 & 0.205 & 0.132 & 0.125 & 0.317 & 0.160 \\
\hline Airplane 4 & 0.186 & 0.202 & 0.120 & 0.214 & 0.184 \\
\hline Airplane 5 & 0.219 & 0.224 & 0.216 & 0.115 & 0.207 \\
\hline
\end{tabular}

This way, it is verified that Airplane 1 is the best option.

\section{Using pairwise comparisons for each criterion}

The same expert who made the judgment of criteria among themselves was asked to make the aircraft pairwise comparisons, for each performance criteria. These comparisons are shown on Tables 4 to 7 .

Table 4. Airplane comparison regarding Maximum Range.

\begin{tabular}{|c|c|c|c|c|c|}
\hline & Airplane 1 & Airplane 2 & Airplane 3 & Airplane 4 & Airplane 5 \\
\hline Airplane 1 & 1 & 1 & $1 / 3$ & 5 & $1 / 5$ \\
\hline Airplane 2 & & 1 & $1 / 3$ & 3 & $1 / 5$ \\
\hline Airplane 3 & & & 1 & 5 & $1 / 4$ \\
\hline Airplane 4 & & & & 1 & $1 / 7$ \\
\hline Airplane 5 & & & & & 1 \\
\hline
\end{tabular}

Table 5. Airplane comparison regarding Cabin Volume.

\begin{tabular}{|c|c|c|c|c|c|}
\hline & Airplane 1 & Airplane 2 & Airplane 3 & Airplane 4 & Airplane 5 \\
\hline Airplane 1 & 1 & 4 & 7 & 4 & 4 \\
\hline Airplane 2 & & 1 & 4 & $1 / 2$ & $1 / 3$ \\
\hline Airplane 3 & & & 1 & $1 / 4$ & $1 / 5$ \\
\hline Airplane 4 & & & 4 & 1 & 1 \\
\hline Airplane 5 & & & & & 1 \\
\hline
\end{tabular}

Table 6. Airplane comparison regarding Baggage Volume.

\begin{tabular}{|c|c|c|c|c|c|}
\hline & Airplane 1 & Airplane 2 & Airplane 3 & Airplane 4 & Airplane 5 \\
\hline Airplane 1 & 1 & 3 & 5 & 5 & 3 \\
\hline Airplane 2 & & 1 & 3 & 3 & 3 \\
\hline Airplane 3 & & & 1 & 1 & $1 / 3$ \\
\hline Airplane 4 & & & & 1 & $1 / 3$ \\
\hline Airplane 5 & & & & & 1 \\
\hline
\end{tabular}


Table 7. Airplane comparison regarding Price.

\begin{tabular}{|c|c|c|c|c|c|}
\hline & Airplane 1 & Airplane 2 & Airplane 3 & Airplane 4 & Airplane 5 \\
\hline Airplane 1 & 1 & $1 / 2$ & $1 / 5$ & $1 / 3$ & 5 \\
\hline Airplane 2 & & 1 & $1 / 5$ & $1 / 2$ & 6 \\
\hline Airplane 3 & & & 1 & 3 & 8 \\
\hline Airplane 4 & & & & 1 & 7 \\
\hline Airplane 5 & & & & & 1 \\
\hline
\end{tabular}

A new Overall Performance Vector can be obtained multiplying a matrix with the performance values of each plane, according to each criterion, by the criteria priorities (Table 1). Table 3 presents this matrix and the decision vectors.

Table 8 Overall performance from pairwise comparisons.

\begin{tabular}{|c|c|c|c|c|c|}
\cline { 2 - 5 } \multicolumn{1}{c|}{} & Max Range & Cabin Volume & $\begin{array}{c}\text { Baggage } \\
\text { Volume }\end{array}$ & Price & $\begin{array}{c}\text { Overall } \\
\text { performance }\end{array}$ \\
\cline { 2 - 5 } & 0.056 & 0.573 & 0.235 & 0.136 & 0.401 \\
\hline Airplane 1 & 0.116 & 0.485 & 0.440 & 0.098 & 0.139 \\
\hline Airplane 2 & 0.101 & 0.095 & 0.259 & 0.135 & 0.116 \\
\hline Airplane 3 & 0.212 & 0.035 & 0.066 & 0.507 & 0.155 \\
\hline Airplane 4 & 0.048 & 0.177 & 0.086 & 0.225 & 0.188 \\
\hline Airplane 5 & 0.523 & 0.207 & 0.149 & 0.036 & \\
\hline
\end{tabular}

This way, as a result, Airplane 1 is still considered as the best option.

\section{Final comments}

The criterion Cabin Volume obtained the highest priority value amongst all other criteria, probably because it was closely related to comfort level, an item that has been more and more required by customers.

The main reasons for the Airplane 1 have showed the highest overall performance were its best performances achieved regarding Cabin and Baggage Volume criteria. This result appeared in both evaluation ways. Notwithstanding, the second evaluation, in which the expert's judgments occurred, showed that the global performance value of this airplane was superior $(0.401$ against 0.246$)$. This fact shows how important it is to use a method that allows performance evaluation based on an expert's judgments. An evaluation based only on numbers and figures, as it occurred on the first evaluation, might not show the importance perceived by experts, who have specific knowledge concerning the problem being studied.

The parameters used for the criteria may be changed by airplane manufacturers, according to their market strategies. Thus, a airplane may have its Max Range increased by the introduction of new fuel tanks or even have its price altered to meet new sale strategies. Therefore, the results presented in this paper may also undergo some alterations due to these changes. 


\section{REFERENCES}

Drucker, P.F.(1967). The effective decision. Harvard Business Review, jan-feb.

Gothb, F. \& Warren, L. (1995). A case study comparison of the analytic hierarchy process and a fuzzy decision methodology. The Engineering Economist, 4, 23-246,.

Kewljets (2008). Dynamic Jet Compare Tool. http://www.kewljets.com/JetCompare..

Lucena, L. F. L. (1999). A analise multicriterial na avaliacao de impactos ambientais. Encontro da Sociedade Brasileira de Economia Ecologica. 13, Recife, Brazil.

Machado, E.P.; Gomes, L.F.A.M. \& Chauvel M.A. (2003). Avaliacao de estrategias em marketing de servicos: um enfoque multicriterio. Revista de Administracao Mackenzie, 4, 61-85.

Murakami, M. (2003). Decisao estrategica em TI: estudo de caso. MSc dissertation (Bussiness Administration). University of Sao Paulo.

National Business Aviation Association (2009). Very Light Jet Training Guidelines. http://web.nbaa.org/public/ops/vlj/.

Saaty, T.L. (1990). Multicriteria decision making: The Analytic Hierarchy Process. Pittsburgh: RWS Publications.

Silva, O. (2008). Jatos Corporativos. Uma Realidade? Aviao Revue, 16, 82.

Strait, B. (2007). The speed of Light. Million Air, may-jun.

Veraldo Junior, L.G. (2008). Gestao do estoque excedente com proposta de reducao utilizando multiplas alternativas atraves de multiplos criterios. MSc dissertation (Mechanical Engineering). Sao Paulo State University. 